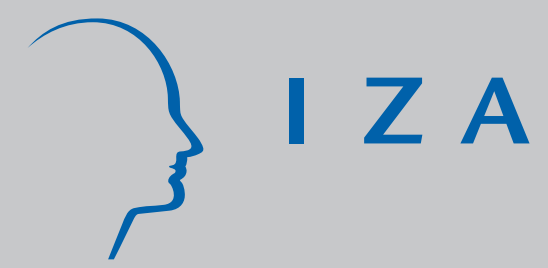

IZA DP No. 8068

The Role of Coresidency with Adult Children in the Labor Force Participation Decisions of Older Men and Women in China

Rachel Connelly

Margaret Maurer-Fazio

Dandan Zhang

March 2014 


\title{
The Role of Coresidency with Adult Children in the Labor Force Participation Decisions of Older Men and Women in China
}

\author{
Rachel Connelly \\ Bowdoin College \\ and IZA \\ Margaret Maurer-Fazio \\ Bates College \\ and IZA \\ Dandan Zhang \\ National School of Development, Beijing
}

Discussion Paper No. 8068

March 2014

IZA

P.O. Box 7240

53072 Bonn

Germany

Phone: +49-228-3894-0

Fax: +49-228-3894-180

E-mail: iza@iza.org

Any opinions expressed here are those of the author(s) and not those of IZA. Research published in this series may include views on policy, but the institute itself takes no institutional policy positions. The IZA research network is committed to the IZA Guiding Principles of Research Integrity.

The Institute for the Study of Labor (IZA) in Bonn is a local and virtual international research center and a place of communication between science, politics and business. IZA is an independent nonprofit organization supported by Deutsche Post Foundation. The center is associated with the University of Bonn and offers a stimulating research environment through its international network, workshops and conferences, data service, project support, research visits and doctoral program. IZA engages in (i) original and internationally competitive research in all fields of labor economics, (ii) development of policy concepts, and (iii) dissemination of research results and concepts to the interested public.

IZA Discussion Papers often represent preliminary work and are circulated to encourage discussion. Citation of such a paper should account for its provisional character. A revised version may be available directly from the author. 


\title{
ABSTRACT \\ The Role of Coresidency with Adult Children in the Labor Force Participation Decisions of Older Men and Women in China
}

\begin{abstract}
Over the course of China's economic reforms, a pronounced divergence in the labor force participation patterns of rural and urban elders emerged - rural elders increased their rates of participation while urban elders reduced theirs. In this project, based on the data of the Chinese population censuses of 1982 and 2000, we employ a two-stage procedure to take into account the endogeneity of the residency and labor force participation decisions of older persons. We find that the effect of coresidency with adult children on the labor force participation of older adult differs by urban vs. rural residence. In 1982, the LFPR of urban elders who coresided with their adult children were significantly higher than those who did not coreside. By 2000, this effect completely disappeared. In contrast, in rural areas, coresidency with adult children had a large and significant negative effect on the labor force participation of both male and female elders. This effect diminished only slightly over the reform period. Finally, we decompose the changes over time in elders' labor force participation decisions and find that the response effect for all groups (male and female, urban and rural) is positive, such that, holding the levels of demographic and economic variables constant, each group of elders would have had higher rates of participation in 2000 than in 1982 . The remarkable divergence in urban and rural elders' labor force participation trends are due to differences in the relative sizes of their attribute and response effects.
\end{abstract}

JEL Classification: J14, J26, J11, J12, J13, J16, J22, O15, O53, P23, R23

Keywords: labor force participation, elders, China, retirement, coresidency, rural and urban, living arrangements

Corresponding author:

Rachel Connelly

Department of Economics

Bowdoin College

9700 College Station

Brunswick ME 04011

USA

E-mail: connelly@bowdoin.edu 
The Role of Coresidency with Adult Children in the Labor Force Participation Decisions of Older Men and Women in China

\section{I: Introduction}

In 2000, China entered the ranks of societies recognized as aging, that is, societies with at least 10 percent of their population aged 60 and above and 7.5 percent aged 65 and above (Cai $e t$ al, 2012, p.12). China's aging process is advancing rapidly: by 2010, 14 percent of the population were already at least 60 years of age and the population share of this age group is expected to rise to 20 percent by 2020 and to 27 percent by 2030 (Wang, 2012). Aging populations bring with them a host of policy issues, including the financing of income security for the aged and issues of who will replace them in the labor force. In China these issues, already very much on the mind of policy makers, are complicated by the large and rapid migration of rural workers to urban centers. The flow of migrants, composed mainly of young people, leads to additional concerns about the elders (and youth) who are left behind in the rural areas. Rural elders have picked up some of the agricultural work abandoned by their adult children, thus increasing the age of their (informal) retirements. In urban areas, formal retirement is fairly widespread. Official retirement ages are quite young in China, a legacy of the excess labor eras of the 1970s, 80s, and 90s. Many policy makers are calling for increases in the official retirement ages to address the changing labor force demographics. These proposed changes to retirement ages carry profound implications not only for the well-being of elders but also their children and their grandchildren as many grandparents continue to provide infant and childcare.

In order to address the policy issues related to China's population aging, we need to understand the recent changes in the labor force participation of elders in both rural and urban 
areas. Urban labor participation rates of Chinese elders fell between 1982 and 2000 while rural participation rates rose. ${ }^{1}$ We are interested in whether the changes in participation are the result of changing demographic characteristics, changes in the roles of demographic characteristics on labor force participation, or changes in institutional and economic elements that are independent of demographic factors. Given rapidly declining fertility rates, increasing educational levels among younger Chinese, increasing rates of migration, and increasing life expectancy, we have plenty of potential smoking guns. We focus here on young elders, those between the ages of 50 and 74. They most likely to be marginal workers, those who might be pushed out of the labor force by a contracting economy or kept in the labor force by changes to institutional retirement ages or by increases in the demand for labor.

We examine the labor force participation decisions of both male and female elders. Women's labor force participation, more than men's, is affected by family composition. ${ }^{2}$ Research on women's labor force participation around the globe has often found that the need to care for children and disabled adults reduces women's labor market employment. However, Maurer-Fazio et al (2011) found that in urban China in 1982, married women's labor force participation rates were 5 percentage points higher in households with young children than in households without young children. On the other hand, coresidence with a disabled adult under age 65 decreased these women's labor force participation by 14 percentage points. By 2000, in urban China, the marginal effect of living with preschool aged children had turned negative, reducing prime-aged women's labor force participation rate by 6 percentage points. Living with

\footnotetext{
${ }^{1}$ We define labor force participation in the traditional way as including both employed individuals and those looking for work. In our census samples, the vast majority of elders in the labor force are employed as opposed to looking for work.

${ }^{2}$ The effect of the presence in the household of young children and elders on men's labor force participation is smaller, and less well studied. In most Western countries, the presence of young children increases fathers' hours of employment, probably to compensate for mothers' reduced hours and to satisfy the higher income needs of families with young children.
} 
a disabled adult, continued to have a large negative impact on prime-aged women's labor force participation rates. These results, based on the data of the 2000 census, are consistent with the findings of studies focused on other countries.

But quite different from that found for other countries is the effect of coresidency with elders on prime-aged urban Chinese women's labor force participation. In Western countries, coresidence most often occurs when elders need help with the tasks of daily living. We thus expect labor force participation to be quite low for older adults who coreside with their adult children. Social scientists have thus focused their investigations instead on the effect of coresidence of parents and adult children on the labor force participation of the prime-age adult children. For example, Heitmueller and Inglis (2007), Johnson and LoSasso (2006), Carmichael, and Charles (2003), Stern (1996), Ettner (1996), Wolf and Soldo (1988) have shown that having an elderly parent living in one's home reduces prime-age married women's labor force participation both in the U.S and the U.K. However, the incidence of coresidence is much higher among Chinese than Western families and the recent research by Maurer-Fazio et al (2011) provides evidence that older adults in urban Chinese households were generally giving rather than receiving care. In their findings, having a coresident parent increased the labor force participation rate of urban (non-migrant) women aged 25 to 50 by 12 percentage points in 2000 . Also, see Chen (2005) and Zhang (2004) for evidence of the productive role coresident elders play in modern urban Chinese households. On the other hand, Liu, et al (2010) found that the labor force participation rate for prime-age women with coresident parents-in-law was reduced when the parents-in-law were in need of care. In this paper we shift the focus of the research question to ask what is the effect of coresidence with adult children on the labor force participation rates of China's older adults? Understanding the role coresidency plays in labor 
force participation rates can help us predict the full effects of changes in formal retirement ages in urban China and the effects of labor migration in rural China on the labor force participation of China's young elders.

Our research is based on data from the 1\% Micro Sample of the 1982 Population Census of China and the $0.095 \%$ Micro Sample of the 2000 Population Census of China. We have invested considerable effort to ensure that variables are comparable across the two censuses. The national coverage and large number of observations allow us a very detailed look at the patterns of both coresidence and labor force participation of China's elderly population.

Even though the incidence of coresidence is much higher in China than in Western nations, one still suspects that elders' decisions on coresidence and labor force participation are very much interrelated. Our empirical model tests and corrects for the potential endogeneity of coresidence using the two-stage residual inclusion method of Terza, Basu, and Rathouz (2008). We find that accounting for the endogeneity of coresidence matters and further that it matters differently for rural and urban residents. For rural men and women in 2000, coresiding with adult children substantially reduces the likelihood that elders are in the labor force. On the other hand, in 2000, coresidency status does not appear to affect whether urban men and women are in the labor market.

In Section II, we discuss a number of factors that are expected to affect the labor force participation rates of elders in urban and rural China. We consider these factors in the context of China's changing economic and demographic environment between 1982 and 2000. Section III presents the basic patterns of labor force participation of older adults over time and across rural/urban location. Section IV presents our findings of the marginal effects of a model of labor force participation that includes a full range of household composition variables. In Section V, 
we employ Borooah and Iyer's (2005) strategy to decompose the changes in participation rates over time into attribute and response effects. Section VI reports our robustness checks. Section VII concludes the paper.

\section{II: Determinants of Labor Force Participation in a Changing Chinese Context}

\section{II.A Theoretical Framework}

Labor force participation can be thought of as the outcome of individual or household calculations of the costs and benefits of an initial hour of employment. ${ }^{3}$ On the cost side is the opportunity cost of the individual's time spent in employment. On the benefit side is earnings or the value of what is being produced (as it would be in farming, for example.)

The opportunity cost of a household member's time is affected by household composition. The presence of young children and others in need of care increases the opportunity cost of the household member's time. Household size might also influence the opportunity cost of time as there will be more domestic tasks to do, but potentially more members to carry out these tasks.

Age is expected to be an important variable in determining labor force participation as it is negatively correlated with good health, fitness, and strength. In addition, we expect that cultural expectations and labor market institutions play a role. For example, the official retirement age in urban China's state-run enterprises sets expectations about retirement ages even for people working in other sectors. In addition, there may be cultural norm effects such that when elders look around and observe that many of their contemporaries are retired, they are more likely to decide that they themselves are of retirement age.

\footnotetext{
${ }^{3}$ If there are substantial fixed costs of employment (either time or money costs) individuals will enter the labor market with hours of work much greater than one. However, the cost benefit calculation is essentially the same.
} 
We also expect differences in labor force participation by industrial sector. In this paper we are mostly concerned with differences across the agricultural and non-agricultural sectors. If one's household is engaged in agriculture, there are numerous tasks, some large, some small, some heavy, some light, to be carried out. The transactions cost of finding employment and getting to and from the location of employment is, in some sense, much lower for farmers than for those working in other sectors. Thus, we expect that the labor force participation rate of elders who live in households engaged in agriculture will be higher than those without someone engaged in agriculture. This concern is not adequately captured by the urban/rural distinction. There are a substantial number of agricultural workers living on the fringes of China's urban centers who are counted in the census as urban residents. We thus control for both urban/rural status and having an agricultural worker in one's household.

Education is increases workplace productivity and consequently compensation and the benefits of employment. It might also increase productivity in the home, but we expect the effect on earnings to be greater. Economic growth such as that experienced in urban China increases the benefits of employment, making more formal jobs available and increasing the monetary compensation of labor market time.

Populations may differ along cultural lines in the ways they value time at home versus time in the market. If a group agrees, implicitly or explicitly, that older people "deserve" to stay at home, its elders will be less likely, all else equal, to be in the labor market than some other group. We do not have any a priori expectations of cultural differences between Muslim and non-Muslim elders in China, but other work on labor force participation in China has found differences in labor force participation across Muslim and non-Muslim ethnic groups (Maurer- 
Fazio, Hughes and Zhang, 2007, Maurer-Fazio, Hughes and Zhang, 2010, and Maurer-Fazio, et al 2011).

Local labor market conditions are also expected to affect labor force participation rates. A growing economy demands workers. Young elders in fast growing areas may elect to stay in the labor market longer than those in low growth areas. High unemployment rates increase search costs and reduce expected wages. Both effects are likely to cause some marginal workers to withdraw from the labor market.

A recent paper by Giles, Wang, and Cai (2011) focuses on two additional individual characteristics that are expected to affect labor force participation of elders: health status and the availability of pensions. They find that both have important impacts on Chinese elders' labor market decisions. Unfortunately the census data do not provide information on either of these factors. Our sample, however, does have the advantage of full national coverage. ${ }^{4}$

\section{II.B Changes in Key Determinants of Labor Force Participation in China 1982 to 2000}

Changes in coresidency with adult children, with one's spouse and with young children-We have identified five mutually exclusive and exhaustive residency categories of older adults based on census categories. They can live alone; with spouse only; with an adult child or child-in-law amongst others including spouse; with children under age 18 and no other adult except possibly their own spouse; and with other related or unrelated individuals. Table 1 shows the distribution for residency categories for urban and rural male and female elders across the two census years.

[Table 1 here]

Table 1 reveals that the proportion of elders age 50 to 74 living with their adult children was quite high in both urban and rural China in 1982. The rate was higher for urban than rural residents. Space constraints may have played an important role in coresidency decisions in urban

\footnotetext{
${ }^{4}$ The Giles et al, 2011 results are based on a survey collected in only two provinces.
} 
areas at that time (Meng and Luo, 2008). Housing shortages caused many adult children to remain with their parents even after marriage. The rate of coresidency amongst elders was high for both men and women, suggesting that widowhood was not necessarily the threshold for joint residency.

Table 1 reveals that by 2000 the proportion of elders living with their children had decreased for both men and women in urban and rural areas. ${ }^{5}$ Since the proportion of elders living with adult children declined, at least one of the other categories must have increased. The living arrangement category with the largest increase was that of living with one's spouse alone. In 2000, 28 percent of rural male elders and 26 percent of rural females elders lived only with their spouses. The comparable percentages for urban elders were 33 percent for men and 29 percent for women.

[Figure 1 here]

Figure 1 reveals the percent of elders of various age categories living with only their spouse. The increases from 1982 to 2000 are larger for the younger age categories than for the older ones. The mean age of those living with their spouse only is younger in the rural areas than in the urban. This is due, in part, to the lower average ages at which rural parents bear children and to higher mortality rates. Living only with a spouse requires that the spouse is still alive and that the children live elsewhere. Longer lifespans have contributed to the former condition and in rural areas, young adults' migration has increased the probability that adult children are elsewhere. Urban-to-urban mobility has resulted in an increase in the number of urban elders lively separately from their adult children. During the period of our study, an active housing market developed in urban areas, reducing the housing shortage and allowing young couples to

\footnotetext{
${ }^{5}$ Our findings echo those of Zeng and Wang (2004), who document a similar decline in the co-residency of elders with adult children from 1982 to 2000 for rural and urban elders age 65 and above.
} 
live separately from their parents. In rural areas also, increased incomes from both rural and migrant endeavors were used to build new houses, which might also have contributed to a reduction of coresidence. We expect that the very nature of coresidency has changed in ways that will impact elders' labor force participation decisions. In both rural and urban settings in 2000, coresidency could be considered more the outcome of choice than it was in 1982 .

However, such choice might well involve matters such as elders substituting for adult children in household chores and in agriculture or elders needing greater care. Each option has a different predicted effect on the effect of coresidency on labor force participation.

In both urban and rural areas in 2000, more than five percent of elders lived in households with children under the age of 18 but with no middle generation present. For rural residents, this is likely the result of the out-migration (to urban areas) of prime-age parents who leave their children behind in the care of the grandparents (Connelly et al, 2012). In urban areas, this phenomenon could also be caused by the out-migration of the middle generation; or by children living with grandparents who supervise their schooling; or by parents who give birth later in life such that they could be over age 50 and yet have own children younger than 18 . For example, if a woman had a child at 35 , her child would 16 years old when she was 51 . Thus, it is possible that at the younger end of the elders' age distribution, coresident children are own children. In such cases, there is no missing middle generation. Figure 2 reveals that there was a sizable share of younger elders living only with children in 1982, especially in rural areas. Given the higher fertility rates of the 1960's and 70's, these households were most likely composed of the relatively older parents whose youngest offspring were still under 18 . However, Figure 2 also reveals that there was a sizable increase from 1982 to 2000 in the incidence of such 
households amongst rural elders aged 60 and over. With these older rural elders, a missing prime-age generation due to out migration is surely the most likely explanation.

[Figure 2 here]

The missing prime-age generation in rural households puts substantial extra pressure on the elders who are left to both take care of farming and look after young children. Two recent papers directly measure the impact of adult children's migration on the time use of elders. $\mathrm{Mu}$ and van de Walle (2011) using the Chinese Health and Nutrition Survey found that rural women aged 51-60 increased their weekly time in agriculture by 4.7 hours if their child was an outmigrant.(p.592) Similarly, Chang, Dong and Macphail (2011), using the same data, find that both rural elder men and women (elder is defined as age 51 plus) increased their hours of offfarm work, farm work, and domestic work by substantial amounts they lived in a household which included outmigrants. Neither paper looks at urban households. In urban households, the likelihood of this double pressure is lessened by the already low level of older women's labor force participation and by the existence of more readily available institutionalized childcare. In the empirical work below, we test the effect of the missing middle generation on young elders' labor force participation.

Changes in education levels-The average level of education was quite low among elders in 1982, most notably among rural women. Ninety four percent of rural women aged 50 to 74 and 56 percent of rural men did not attain primary school graduation in 1982 . At the other end of the education spectrum, less than 0.1 percent of rural women elders and 2 percent of rural men had attended senior high school. By 2000, we find that the share of rural female (male) elders who failed to graduate from primary school had declined to 52 percent (20 percent), while high school graduation still remained less than 0.1 percent ( 4 percent). 
By 2000, the new generation of urban elders had higher average educational attainment than the urban elders of 1982. In 1982, 72 percent of urban women and 28 percent of urban men had failed to graduate from primary school and only 4 percent and 11 percent managed to attend senior high school. In 2000, 30 percent of urban women and 8 percent of men failed to graduate from primary school and 14 percent of women and 28 percent of men had attended high school. We expect that these substantial changes in the education levels will impact labor force participation rates, particularly in urban areas where official retirement ages differ by occupation in ways that are highly correlated with educational attainment.

Changes in the mean age of elders-One might expect that increases in life expectancy and the baby booms and busts of the past would increase the mean age of the group aged 50 to 74 . However, China's population increases over the better part of a century have yielded increasingly larger cohorts of younger elders. The net result is that the mean age of the group aged 50 to 74 has remained nearly static between 1982 and 2000 in both rural and urban areas and for both men and women. The mean age is between 59 and 61 for each group in each period of our study.

Changes in local labor market conditions-- Certainly, the substantial changes in the basic economic structure of the economy of China from 1982 to 2000 can be expected to change, in many fundamental ways, the decision making of elders about their labor force participation. For the elders of 2000, it is quite likely that their earlier expectations of the future turned out to be poor predictors. Many of their urban work units closed and their expected pensions were reduced (or disappeared) due to enterprise bankruptcy and by the high rates of inflation in the 1990s. In order to reduce employment rolls companies encouraged the retirement of middle-aged workers. 
In the same time period, urban income increased. The increased wealth allowed elders to stay laid off. High unemployment rates also discouraged elders from returning to the labor market.

For rural workers, the dismantling of the collective farms and return to family farming increased the benefits to hours of employment for rural elders. The decade of the 1990s also witnessed massive increases in migration, which drew younger men and women away from rural areas, leaving elders in charge of both farming and, in many cases, grandchildren.

\section{III: Patterns of Labor Force Participation of China's Population Aged 50 to 74}

When China counted itself in 1982, the year of the first national census of the post-Mao era, the labor force participation of prime-age workers was extremely high. The labor force participation rates (LFPR) of both urban and rural prime-age men in 1982 were over 90 percent $^{6}$ within the entire 25-to-50 age range. The LFPR of married urban and rural women aged 25 to 50 was also extremely high at 87 and 84 percent. However, women's rates, unlike men's, were not uniformly high, rather they declined rapidly after age 40. By age 50, urban women's LFPR was 52 percent and rural women's was 59 percent.

The data of the 1982 census further reveals that the rapid decline in LFPR for women continued beyond age 50, following a similar pattern for both urban and rural women. By age 65, the LFPR were 9 percent and 11 percent for urban and rural women, respectively. The participation rates of older men declined to 41 and 54 percent for urban and rural men by age 65 .

Now fast forward to the year 2000 when China counts itself again after more than two decades of massive economic reform. For elders aged 50 to 74, the divergence in labor force participation trends of urban and rural residents is quite startling. In this 18 -year period, the LFPR of rural women aged 50 to 74 increased from 28 percent to 59 percent. The rate of rural

\footnotetext{
${ }^{6}$ Throughout this section, the LFPR for 1982 and 2000 are based on the authors' calculations using sample data of the 1982 and 2000 Population Censuses of China.
} 
men increased from 71 percent to 79 percent. During the same period, the labor force participation rate of urban women of the same age group decreased slightly from 23 percent to 21 percent while the rate for urban men of the same age group fell substantially from 65 percent to 47 percent. The decline in the labor force participation of China's urban elders stands in contrast to the trend in many developed countries where the labor force participation of elders has increased in recent years. For example, in the U.S. women over age 54 had a labor force participation rate of 24 percent in 1994 and 30.5 percent in 2004. (U.S. Department of Labor, 2005)

Table 2 shows LFPRs by age category. Looking down the columns of Table 2 we see that, as expected, labor force participation rates decline with age, but the patterns are quite different for urban and rural workers. For urban men, the institutionalized retirement ages of 55 and 60 are quite evident, while the decline in participation is more gradual for rural workers. Giles et al (2011), employing different data sources, report similar retirement age distributions. Official retirement ages in urban China vary by gender and occupation, but the occupational differences are highly correlated with education. For example, ordinary women urban workers retire at 50, while women working in a heavy physical labor retire at 45 . A woman government

worker retires at 55 , but if she is in a leadership position then at age 60 . For men, add five years to the women's retirement ages in most categories with some compression at the upper ages. In the multivariate analysis below the differences in urban labor force participation by education level become quite apparent.

\section{IV: Determinants of Labor Force Participation}

Given the observed increases in the labor force participation rates of male and female rural elders and the decreases in the labor force participation rates for urban male elders, we are 
interested in seeing how the determinants of elders' labor force participation have changed over time. Our model of labor force participation places special emphasis on the role that familial obligations. Employing the two-stage residual inclusion model introduced by Terza, Basu, and Rathouz (2008), Maurer-Fazio et al (2011) modeled coresidency with parents or parents-in-law, with elders 75 years or older, and with children under age 6 as variables that were (potentially) endogeneously determined. Their empirical work revealed that the concern with endogeneity of coresidence with parents or parents-in-law and with elders 75 years or older was well founded, but that coresidency with children under age 6 was exogenous. Here we model the potential endogeneity of coresidence with one's adult children, but assume that other coresidency variables are exogeneous. We also employ the two-stage residual inclusion model of Terza, Basu, and Rathouz (2008). The first stage is a reduced form coresidency equation, while the second stage is a labor force participation equation, which includes both coresidency with adult children and the residuals of the coresidency equation as separate independent variables. The work of Terza, Basu, and Rathouz (2008) has demonstrated that this two-stage model leads to consistent estimates of all coefficients. The resulting marginal effect of the coresidency variable can be interpreted as the exogenous portion of the effect, while the marginal effect of the residual can be interpreted as a measure of the relationship of the unobserved characteristics correlated with the choice to coreside with one's adult children to the choice elders make to participate in labor markets.

The variables in the labor force participation equation include: age in five year categories, coresidency with adult children, coresidency with children of various ages, coresidency with parents or parents-in-law, current marital status, educational attainment, an indicator of whether anyone in the household is employed in agriculture, an indicator of whether the elder is a 
member of one of China's ethnic Muslim minorities, and, to account for exogenous differences across locations, a set of the prefecture and provincial contextual variables. We used the census data to calculate prefectural unemployment rates, sex ratios at birth, and illiteracy differential between men and women, as well as the share of the prefectural population that belongs to Muslim ethnic minorities. ${ }^{7}$ The unemployment rate is included to explore the hypothesis that high rates of unemployment discourage older workers' participation in labor markets. The sex rate at birth and the illiteracy differential between men and women are included to test whether areas that differ in gender disparity also differ in labor force participation rates. We include both provincial urban (or rural) per capita mean incomes and provincial GDP growth rates over the 5 years preceding the census to control for the different economic fortunes of the elders residential locations.

The identifiers in the first-stage coresidency equation are two prefectural-level variables: the mean rates of coresidency of married and not married elders. These two variables, which allow for the possibility that location-based norms affect individual decision making, are strong predictors of coresidency. They are included in the first stage equation and excluded from the second stage. Slightly different treatments of age and marital status also serve as identifiers of the residuals included in the second stage equation.

The effect of coresidency with young children (mostly grandchildren) is one of the variables that we are most interested in since it signals the increased home production needs of households. Given the finding of Maurer-Fazio et al (2011) that the presence of elders increased the labor force participation of prime-aged urban women, we expect to find reduced labor force participation of elders who live in households where young children are present. This would

\footnotetext{
${ }^{7}$ A prefecture is a Chinese administrative unit that is one level below provincial units and one level above county units. There are approximately ten times as many prefectures as provinces and ten times as many counties as prefectures.
} 
occur if those elders supply labor in the household to free prime-age women (often their daughters-in-law) to work outside the home. Given this expected interaction between generations, when prime-age woman are missing from elders' households, we expect some limitations on the elders' ability to withdraw from the labor market. Thus, we test whether the presence of young children plays differential roles on elders' labor force participation, depending on the presence or absence of prime-age household members by including indicator variables for the presence of children of various ages in households with no adult children present. As discussed above, for the youngest elders, it is possible that the children we observe in the household are own children, but especially by 2000 , these households are more commonly households where young children and grandparents are living together while the children's parents are elsewhere. We predict that, especially in rural areas, the missing prime-age generation will increase the probability that elders are in the labor market.

We run the model separately by sex and rural/urban residence and, of course, by census year. We will discuss the results across years, separately by sex and location. We begin with urban women and then compare their results to those of the urban men. We then discuss our findings for rural men and women and make comparisons both between sexes and across locations.

\section{IV.A. Labor Force Participation of Older Urban Non-Migrant Women, 1982 and 2000}

Table 3a compares the marginal effects of the explanatory variables of our model of labor force participation across the two censuses for urban women. In our analysis of the 2000 data, we limit the sample to non-migrant women. ${ }^{8}$ The characteristic of prime concern here is the effect of coresidency with adult children, which for urban women in 1982 is positive, but

\footnotetext{
${ }^{8}$ Maurer-Fazio, et al (2011) found that prime-age migrants from rural areas, currently living in urban centers, differed substantially from urban non-migrant residents in terms of their labor force participation decision making.
} 
becomes insignificant in 2000. Table 3a reveals that the size of the marginal effect falls from .181 in 1982 to -.007 in 2000 , indicating a reduction in the exogenous effect of coresidency on labor force participation of urban women elders. The residual of coresidence is negative and significant in both years, but here too the absolute value of the marginal effect diminishes over the period of analysis. The negative sign on the coefficient on the residual indicates that the characteristics correlated with the choice to coreside with adult children reduce labor force participation. Poor health is a good example of a characteristic that would increase coresidency and reduce labor force participation. The census data do not provide any indicators about elders' health status. When we deliberately ignore the potential endogeneity of the coresidency decision and rerun the model as single stage, we find negative and significant effects of coresidency on elder urban women's labor force participation in both years. This net marginal effect of coresidency, which combines both the exogeneous component and the residual, is approximately equal to the sum of the two marginal effects from the two-stage model. For example, when we estimated a model which omitted the residual (thus ignoring the potential endogeneity) the marginal effect of coresidency with adult children in 2000 is -.026 and is significant at the .01 level. Thus, we conclude that older urban women who live with their children are somewhat less likely to be employed than those who live independently, but for reasons other than the coresidency per se.

[Table 3a here]

The other variables of central interest are the effects of coresiding with young children. Table 3a shows that coresiding with children aged 0 to 5 or 6 to 12 reduces the labor force participation probability of urban women elders in both years and that coresiding with children aged 13 to 17 reduces the labor force participation rates of elderly urban women in 2000 . This is 
what we expected to find as the flip side to Maurer-Fazio et al's (2011) result that coresidency of the prime-age urban women with parents or parents-in-laws and any elder over age 75 increased the labor force participation of the prime-age women. It seems clear now, from both sides, that many of these older women are acting as caregivers for children instead of remaining in the labor market. Since the presence of 13 to 17 year olds also reduces urban women elders LFPR it seems clear that caregiving goes beyond the physical care of very young child and includes the education facilitating care of older children. ${ }^{9}$

In households with no prime-age adults present, the coefficient on school-age children is large and positive to such an extent that this interaction term outweighs the negative general effect of the presence of school-age children in elder women's households. In other words, there is a net positive effect of the presence of older children on the labor force participation of urban elders whenever the adult children are absent.

The last coresidency variable of particular interest here is that of elders coresiding with their own parents or parents-in-law. In 2000, 4 percent of urban women aged 50 to 74 coresided with their own parents or parents-in-law. These female elders are three percentage points more likely to be in the labor market than those not coresiding with parents or in-laws, all else equal. This may be due to having someone at home to cover the housework, or to increased income needs due to higher numbers of dependents in the household and to the health care expenses of the very elderly.

The age category of the elders matters in the way we expect, that is, the probability of labor force participation falls with age. The decline is more gradual in 2000 than it was in 1982. Urban widows are less likely to be employed than currently married women. Labor force

\footnotetext{
${ }^{9}$ This fits with Zeng and Xie's (2011) finding of the role of coresiding grandparents in the educational attainment of rural children.
} 
participation increases with education with the strongest effects at the highest levels of education. ${ }^{10}$ Having an agricultural worker in the household not only has a very large positive effect on the labor force participation of female urban elders, but also has increased substantially over the 18-year period. In 2000, urban women who live in households engaged in agriculture are 55 percentage points more likely to be employed than urban women in non-agricultural households. Finally, in terms of individual level variables, there is no effect on urban women elders' labor force participation rates of being a member of a Muslim minority.

Some of the contextual variables do affect individual labor force participation rates, particularly the prefectural unemployment. Higher rates of unemployment discourage the labor force participation of urban female elders. This effect is especially noticeable in 2000 . The percent Muslim minority in the prefecture increased employment in 1982, but decreased employment slightly in 2000. Per capita income levels and GDP growth levels switched signs between 1982 and 2000. Finally, areas with greater discrepancies by sex in illiteracy rates have higher levels of women's employment in both years. Discrepancy in the sex ratio at birth from its natural rate is also associated with higher levels of women's employment in both years but is only significant in 1982

\section{IV.B. Labor Force Participation of Urban Non-Migrant Elder Men, 1982 and 2000}

The results of the labor force participation equation for urban elder men can be found in Table 3b. As with urban non-migrant elder women, the exogenous effect of living with one's adult children is positive and fairly large in 1982 for urban non-migrant men. The coeffiecient on the residual is also large but negative. Again, as with urban elder women, in 2000 for urban

\footnotetext{
${ }^{10}$ Giles et al, 2011 find a U-shaped pattern for urban women where employment declines through the completion of middle school. We believe the difference between their results and ours might be attributed to their more modest sample size, differences in the timing of the study, or that they consider employment rather than labor force participation.
} 
male elders, the effect of coresiding with adult children is insignificant. The estimated marginal effect is small as is the effect of the residual. When we estimate the model without the residuals, the resulting marginal effects are negative and significant, reducing labor force participation by 5 percentage points. Thus, overall, urban men who coreside with their adult children are slightly less likely to be in the labor market, but mainly because of the negative correlation with unobservables in the coresidency and participation decision.

[Table $3 b$ here]

Coresiding with young children reduces the labor force participation of urban elder men just as it did for urban elder women, but no positive effects of living in a household with missing adult children are observed. Like urban women, urban male elders who live with their own parents or parents-in-law are more likely to be employed.

Other individual level variables for urban men behave very much the way they did for urban women. The decline by age is quite steep in 1982 and less steep in 2000. Widowers are less likely to be in the labor market than married men. This might indicate a correlation in health status across couples, the increased income needs of an extra person in the household or a cultural definition of "old" associated with widowhood.

Those with the highest education are most likely to be labor market participants. This is not surprising, given the institutional structures governing retirement ages, which are graduated by education/occupation with higher educated workers expected to work longer. Retirement ages are probably also correlated with the physicality of the work in which many men are engaged. However, in 2000, those with the lowest level of education are also more likely to be in the labor market than those who graduated middle school (the omitted category). This may indicate greater financial needs and lack of state pensions for those with the lowest levels of 
education. The lack of state pensions is also part of the reason why having an agricultural worker in the household has a significant, large, positive, and increasing effect on the participation rates of urban elder men. We observed similar effects of these variables for urban women.

The contextual variables for urban elder men reveal that high prefectural unemployment rates discourage urban men from being in the labor force just as they did for urban women. This effect is consistent across the two censuses, not limited to the more recent period when unemployment rates were much higher. The unemployment rates may be serving, more broadly, as proxies for the economic health of a region. For urban elder men, provincial urban income and GDP growth rates are positively related to labor force participation. For urban elder women, the effects of these variables are quite muted in 2000 with GDP growth rate having a negative effect. Overall, the participation rates of urban elders seem to be more affected by individual characteristics than macroeconomic effects.

\section{IV.C. Labor Force Participation of Rural Women and Men Elders, 1982 and 2000}

Table $3 \mathrm{c}$ presents the labor force participation results for rural women elders and Table $3 \mathrm{~d}$ presents the results for rural men elders. By comparing these results to those of urban elders, we conclude that coresidency with adult children is a very different phenomenon in rural versus urban China. For both rural men and women, coresiding with one's adult children substantially reduces labor force participation. For rural women, residing with adult children reduces participation rates by 29 percentage points in 2000 . For men the reduction is 22 percentage points. One can hypothesize that the work of elders and others in rural areas is highly substitutable. We would not expect this to be true in urban areas where elders and others are typically employed in quite different endeavors. 
[Table $3 \mathrm{c}$ and $3 \mathrm{~d}$ here]

The potential substitutability of work between younger and older household members of agricultural households can also be seen in the effect of coresiding with young children. In rural areas by 2000, these young children are almost certainly grandchildren. In Table $3 c$, we see that in 2000, coresiding with grandchildren reduces elderly women's or men's participation rates and that the participation of elders is lower in households with school-age or teenagers than with preschoolers. Older school-age children and teenagers appear to be picking up some of the farm work. However, in 2000, in households with no prime-age household member present, living with grandchildren increases elders' participation rates by 11 percentage points for women with school-aged grandchildren and 6 percentage points for men with school-aged grandchildren, compared to those with adult children present. For female rural elders, the group who have experienced the largest increase in labor force participation, the size of these positive participation effects of the presence of children and the missing middle generation has grown over the 18-year period.

The final variable of interest related to coresidence is that of coresiding with parents or parents-in-law. For female rural elders, coresiding with a yet older generation increases the probability of participation by 6 percentage points in 1982 and by 7 percentage points in 2000 . For rural men, the marginal effects are smaller and insignificant.

The age gradient for participation is much steeper for rural elders than urban, due partly to the institutionalized retirement ages in place for urban workers. For rural women, the age gradient has become steeper over time, while for men it appears almost unchanged. The education gradient differs between rural men and women. For rural women, there is a very strong negative effect on labor force participation of not graduating from primary school and a 
strong positive effect of obtaining a high school or better education. This is similar to the education gradient for urban women, although the negative marginal effect of not graduating from primary school is much larger for rural women and applies to a larger share of rural women than urban. For rural men in 2000, the education gradient is reversed. Those with the lowest level of education are more likely to be in the labor market and those with the highest level are the least likely. This may be the result of an income effect, but it is strange that it would be the case for rural men but not rural women. ${ }^{11}$

For both rural men and rural women, being widowed reduces labor force participation. Recall this was also the case for urban men and women. Not all households in rural China have agricultural workers in them, but, of course most do. In the 2000 data, approximately 85 percent of rural households included an individual who listed his or her occupation as farming. Elders living in such households are substantially more likely to be in the labor force. The rural agricultural worker effect is even larger than the urban agricultural worker effect and has grown substantially over the 18 year period.

The final individual level variable included in Tables $3 \mathrm{c}$ and $3 \mathrm{~d}$ is an indicator variable representing membership in one of China's Muslim ethnic minority groups. The effect for rural men and women is positive and significant and consistent across the two censuses. Recall that for urban dwellers this variable was insignificant. As we observed with urban men and women, the unemployment rate in the prefecture is negatively correlated with labor force participation for both rural men and women. Male bias as measured by a higher sex ratio at birth and larger differences in literacy rates between men and women is associated with higher LFPR for rural women in 2000 and lower LFPR for rural men (from the literacy gap only). It is not clear why this should be the case, unless it represents differential work patterns that favor men that exist all

\footnotetext{
${ }^{11}$ Giles et al, 2011 find a negative education /employment relationship for both rural men and rural women.
} 
the way through to old age. The other contextual variables provide mixed results, which are difficult to characterize.

\section{V: Accounting for Changes in Labor Force Participation over Time}

Our introductory discussion focused on the changing environments of Chinese

households between 1982 and 2000. We considered changes in the institutional structures of labor markets that resulted from the implementation of economic reforms in both rural and urban areas during this period. Incomes increased for most households, especially for urban and rural households in coastal areas. Light manufacturing and service sectors expanded greatly during this period. Each of these changes is expected to affect labor force participation rates of China's older population. We also highlighted changing individual and household demographics, which we have shown to impact labor force participation. The educational attainment profiles of elders in 2000 differ from those of elders in 1982. The shares of elders coresiding with adult children and with young children have also changed.

Given the extent of labor market and demographic change, it would be interesting to know what role changes in demographic attributes play relative to changes in labor market behavior. The usual strategy for exploring similar questions is to employ the Oaxaca-Blinder decomposition, or its non-linear equivalent strategy. But the results of these traditional strategies depend on which group (in our application, the groups are census years) one uses as the base for setting the mean characteristics. A new decomposition technique provides a solution to this concern. The Borooah and Iyers (2005) decomposition strategy uses the sample mean for the full sample (in our case, both census years) to calculate the effect of the changing coefficient vectors on the dependent variable. 
Table 4 presents the results of the Borooah and Iyers decomposition for each of our four population segments (rural/urban, male/female). The first column reports the observed change in the proportion of the young elder group in the labor force between the two census years. The second column reports the response effect, which estimates the share of the change that is the result of differences in behavior (differences in the coefficients). The final column reports the attribute effect, the share of the change in participation rates that is the result of differences in individual, household and contextual characteristics (differences in the X's).

It is clear from column one and already well known to readers that the size and direction of the observed changes varies substantially by location and gender. However, once we decompose the changes into response effects and attribute effects, we find similar patterns across these subsets of the population. Each subset had a positive response effect between 1982 and 2000. This means that changes in the marginal effects (how a given characteristic translates into labor force participation) predict increased labor force participation for each of these subsets of Chinese elders. Thus, new opportunities provided by a growing economy, increased emphasis on individual responsibility for income level, growing inequality, increased costs of health care, increased compensation for effort, increased healthfulness of the young elder group, and the increased availability of consumer goods all seem to have contributed to changes in the ways that elders make labor market participation decisions. At the same time, however, three out of our four subsets experienced a negative attribute effect, that is, changes in the groups' characteristics alone would have predicted a decline in labor force participation. Only rural women show a positive attribute effect and that effect is small.

Despite the similarities, differences in the magnitudes of the response and attribute effects lead in the end to the very different overall patterns we observe across groups. For rural 
men and women elders between 1982 and 2000, the response effects dominate and labor force participation increases. For urban men and women, the attribute effects dominate leading ultimately to their reduced labor force participation rates.

[Table 4 here]

\section{VI: Robustness Checks}

One of our concerns, when specifying the model, was the possibility that the 50 to 64 year old group might behave differently than older elders. After all, those aged 50 to 64 would be considered more likely to be in the labor force and less likely to coreside with adult children. In order to test this hypothesis we estimated our model for the younger subsample only. The results for the younger group were almost identical to the results based on the full sample and thus are not included here. Thus, the decisions about labor force participation of 50 to 64 year olds appears to be affected by individual, household, and contextual level variables in the same way as the older group. Similarly, we re-ran our model on an expanded sample that included elders from age 50 to 84 . Once again, we found no substantive differences in our results when we included these older individuals. Given the current policy debate and discussion focused on increasing retirement ages for China's urban workers and the changing time demands on the younger group of rural elders, we decided to focus our exposition on the group most likely to be affected, those from 50 to 74 .

In addition, as reported above, we also re-ran each model deliberately ignoring the potential endogeneity of coresidence with adult children. The marginal effect of coresidence with adult children in the single-stage models were negative in each case with effects smaller in magnitude than those reported in Tables 3a-3d. However, the marginal effects of the other 
variables were quite robust to the omission of the residual term. Coresiding with one's adult children appears to be orthogonal to other determinants of labor force participation.

\section{VII: Conclusion}

This paper focuses on the labor force participation decisions of elders in China and the impact of coresidency on those decisions. Coresidency with adult children continues to be very common among Chinese elders in 2000 despite large societal changes. Interestingly, the proportions of Chinese elders who coreside with their adult children are very similar in rural and urban areas although the motives may be quite different.

For rural men and women, coresiding with adult children substantially reduces the likelihood that elders are in the labor force. We speculate that this is the result of both the high rate of substitutability of workers within agriculture and also the heavy physical demands of farming. The situation differs for urban elders, for whom by 2000, coresidence with adult children had no discernable effect on the labor force participation of urban elders, whether male or female.

When an elder's household also includes a prime-age adult, coresidency with young children exerts a universally negative effect on elders' labor force participation (for men and women, urban and rural). This result reinforces the findings of Maurer-Fazio et al (2011), which focused on the labor force participation of prime-aged urban women and found that those living with elders were more likely to be in the labor force. It appears that, in general, when children are present in the household, elders contribute to the household tasks related to the presence of children. Such tasks may include the supervision of the children's homework. ${ }^{12}$ The recent discussion of raising retirement ages in urban China and equalizing the retirement ages for men and women has ignored one important potential side effect of so doing-many of China's elders,

\footnotetext{
${ }^{12}$ Zeng and Xie (2011) report improved educational attainment in rural households with coresident grandparents.
} 
especially women, are providing the child care that enables prime-age women to remain in the labor force. Raising women's retirement age to that of men in an attempt to address labor shortages, slow shrinkage of the labor force, or reduce the ratio of the retired to employed populations may inadvertently cause younger women to drop out of, or fail to re-enter the labor force after childbirth due to lack of child care.

According to the 2000 census data, about 4 percent of rural elders were living in households that included young children, but lacked any prime-aged adult. This type of household composition arises most commonly due to the out-migration of rural parents who leave their children behind in the care of grandparents. In such households, rural male and female elders have much higher rates of labor force participation than those in households where the prime-age adults are present. In these households, the net effect of coresidency with young children on the labor force participation of elders is positive. Despite the remittances sent home by migrant adult children, it appears that such elders are bearing the double burden of providing their own support via farming and caring for the left-behind children. ${ }^{13}$

Being a widow or a widower has a consistently negative effect on labor force participation, controlling for age and education, in both urban and rural areas. Widowhood appears to be a transformative event for many Chinese families. When a spouse dies, it appears to be a sign that the surviving spouse is "old," and it is time to hand over control to adult children and withdraw from labor force. This participation effect is in addition to the effect of widowhood on coresidency. In the first stage equations, widowhood is a strong predictor of coresidency, which further reduces labor force participation for rural men and women (but has no effect for urban).

\footnotetext{
${ }^{13}$ These results echo those of Chang, Dong and MacPhail (2011) and Mu and van de Walle (2011) using the CHNS.
} 
A decomposition of the sources of the observed changes in labor force participation over time found consistency across each of the male, female, urban, and rural groups despite noticeable differences in observed rates labor force participation across these subsets of the elderly population. For each of the four groups, the effect of the changes in the coefficients, the response effect, which represent changes in decision-making, were positive. Elders in each of the four groups, holding demographic and economic variables constant, are choosing to remain in the labor force longer. That is, holding attributes constant, elders would have had higher participation rates in 2000 than in 1982. The changes in demographic and economic variables alone, holding the coefficients constant, would have reduced labor force participation for all but rural women and even there though the effect was positive, it was very small in magnitude. The remarkable differences in observed trends in rural and urban elders' labor force participation are due to differences in the relative sizes of the attribute and response effects.

Inclusion of information on the health status of elders, a factor not tracked in the census data that underlies our analysis, would make a valuable further contribution to our understanding of elders' participation decisions. Of course, information on individual and household incomes and/or wealth levels would also be useful. In addition, we readily acknowledge that our most recent data, that of the 2000 population census, are already more than a decade old. To date, the micro data of the 2010 census have not been publically released, so we, as well as others, will need to look beyond the population censuses for more recent sources of information on elders' labor force participation. 
Table 1: Living Arrangements of Persons Aged 50 to 74 in Rural and Urban China (\%)

\begin{tabular}{|l|rr|rr|rr|r|r|}
\hline \multirow{2}{*}{} & \multicolumn{4}{|c|}{ Rural } & \multicolumn{4}{c|}{ Urban } \\
\cline { 2 - 9 } & \multicolumn{2}{|c|}{ Men } & \multicolumn{2}{|c|}{ Women } & \multicolumn{2}{c|}{ Men } & \multicolumn{2}{c|}{ Women } \\
\cline { 2 - 9 } & 1982 & 2000 & 1982 & 2000 & 1982 & 2000 & 1982 & 2000 \\
Living alone & & & & & & & \\
Living with spouse only & 6.59 & 6.10 & 5.69 & 5.09 & 5.66 & 4.84 & 6.13 & 6.30 \\
Living with adult children/children-in-law & 13.63 & 28.87 & 10.52 & 26.16 & 12.95 & 33.16 & 10.04 & 29.05 \\
Living with children<18: no other adults & 59.27 & 53.82 & 63.41 & 58.63 & 67.84 & 55.50 & 68.41 & 58.15 \\
except possibly spouse & 17.70 & 8.41 & 18.62 & 9.30 & 11.11 & 5.05 & 12.95 & 5.60 \\
Other & & & & & & & & \\
\hline
\end{tabular}

Source: Chinese Census 
Figure 1a: Percent of Rural Persons Aged 50 to 74, Living with Spouse Only

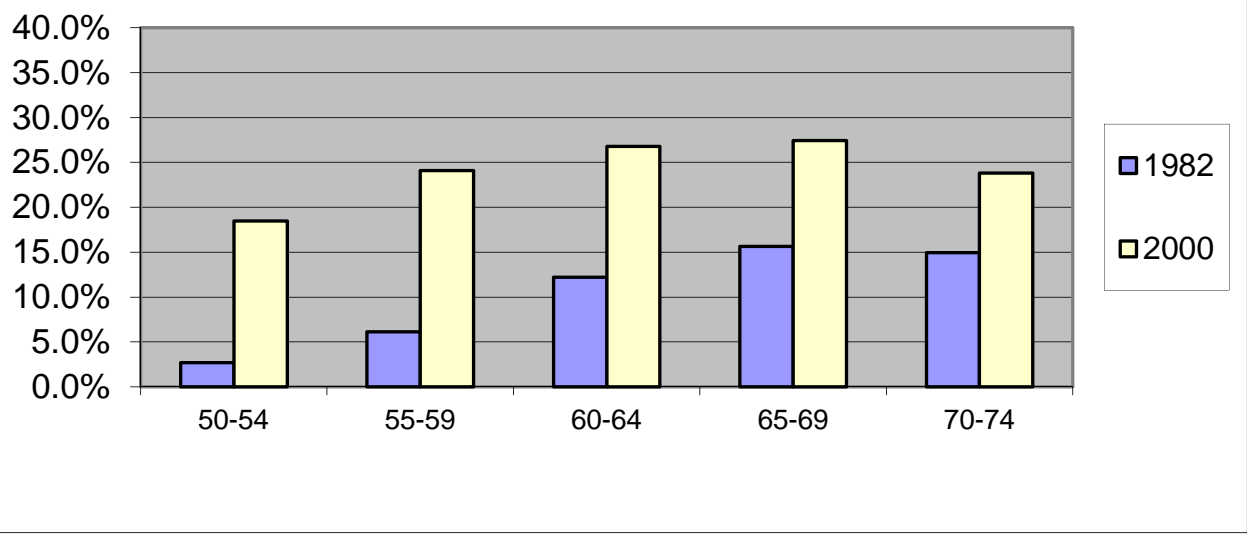

Figure 1b: Percent of Urban Persons Aged 50 to 74 Living with Spouse Only

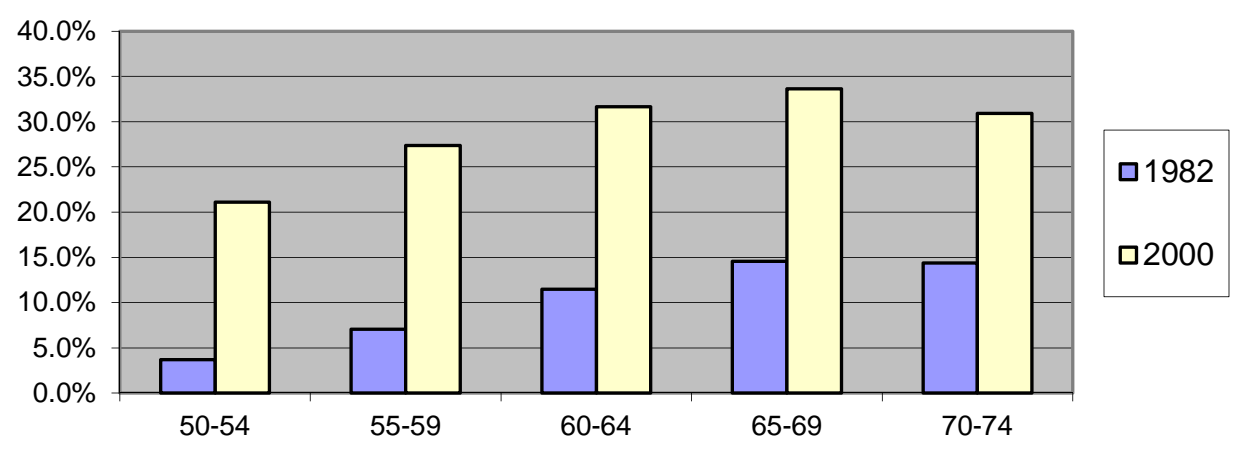

Source: Chinese Censuses 

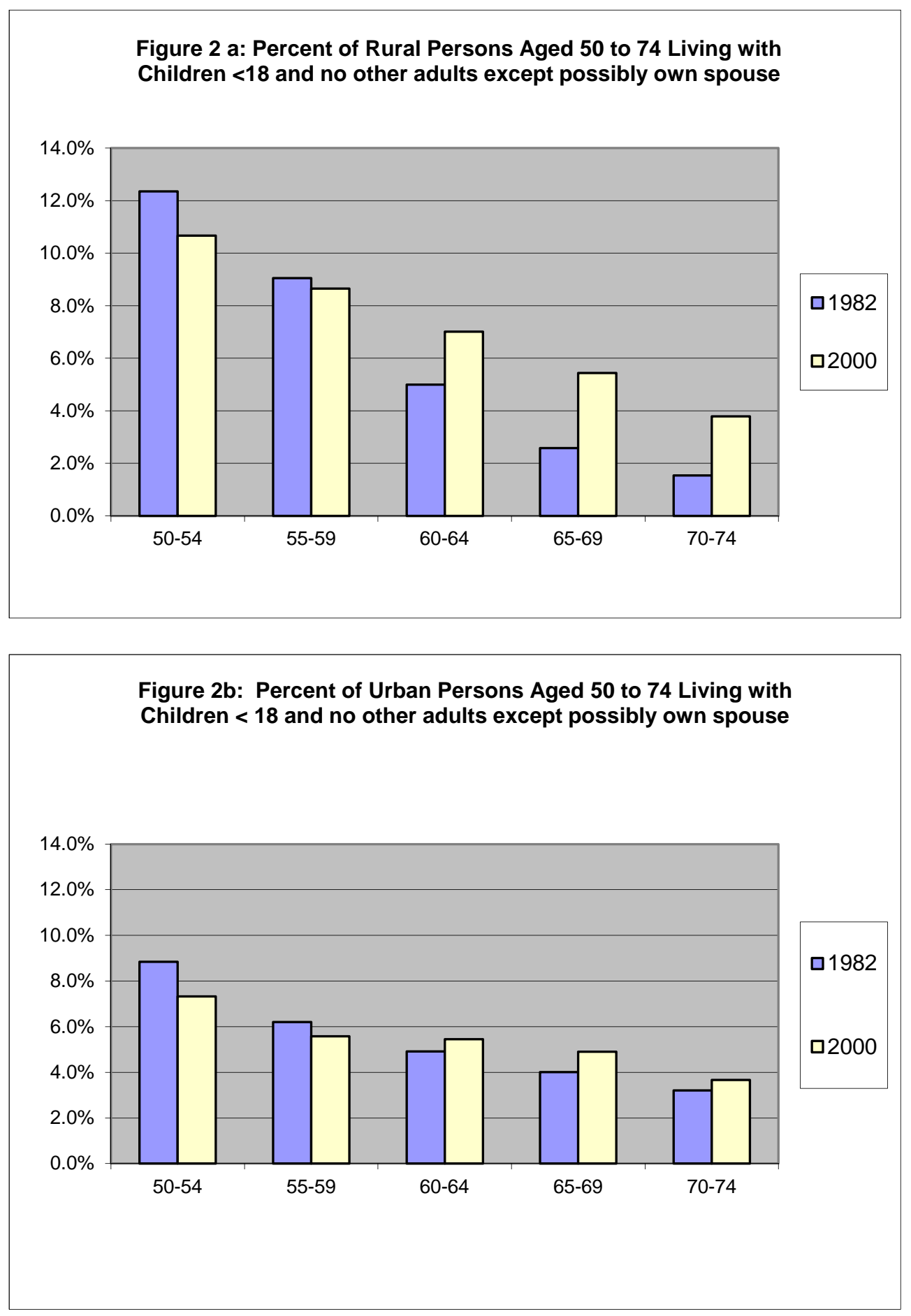

Source: Chinese Censuses 
Table 2: Labor Force Participation Rates by Age, Sex, Rural/Urban Location and Census Year

\begin{tabular}{|l|rr|rr|rr|rr|}
\hline \multirow{2}{*}{} & \multicolumn{4}{|c|}{ Rural } & \multicolumn{3}{c|}{ Urban } \\
\cline { 2 - 10 } & \multicolumn{2}{|c|}{ Men } & Women & \multicolumn{2}{c|}{ Men } & \multicolumn{2}{c|}{ Women } \\
All elders, 50 to 74 & 1982 & 2000 & 1982 & 2000 & 1982 & 2000 & 1982 & 2000 \\
\cline { 2 - 10 } 50 to 54 & $71.2 \%$ & $78.5 \%$ & $27.9 \%$ & $58.9 \%$ & $65.3 \%$ & $46.6 \%$ & $22.7 \%$ & $20.7 \%$ \\
55 to 59 & & & & & & & & \\
60 to 64 & $92.0 \%$ & $91.8 \%$ & $52.7 \%$ & $81.8 \%$ & $89.4 \%$ & $79.8 \%$ & $40.5 \%$ & $39.1 \%$ \\
65 to 69 & $84.0 \%$ & $89.7 \%$ & $34.8 \%$ & $71.5 \%$ & $75.4 \%$ & $59.9 \%$ & $24.8 \%$ & $21.6 \%$ \\
70 to 74 & $65.6 \%$ & $76.7 \%$ & $17.2 \%$ & $54.1 \%$ & $52.0 \%$ & $27.5 \%$ & $13.5 \%$ & $13.0 \%$ \\
& $46.6 \%$ & $61.2 \%$ & $8.0 \%$ & $37.0 \%$ & $36.0 \%$ & $18.1 \%$ & $7.8 \%$ & $8.2 \%$ \\
\hline
\end{tabular}


Table 3a: Comparison of the Determinants of Labor Force Participation for Urban, Non-Migrant, Women, Aged 50 to 74

\begin{tabular}{|c|c|c|c|c|c|c|}
\hline \multirow{2}{*}{ Coresidence with adult children variables } & \multicolumn{3}{|c|}{1982} & \multicolumn{3}{|c|}{2000} \\
\hline & \multicolumn{2}{|c|}{ Marginal Effect } & Means & \multicolumn{2}{|c|}{ Marginal Effect } & Means \\
\hline Coresides with adult children & 0.1812 & $* * *$ & 0.764 & -0.0065 & & 0.593 \\
\hline Residual of coresidence with adult child & -0.2795 & $* * *$ & 0.000 & -0.0193 & & 0.000 \\
\hline \multicolumn{7}{|l|}{ Other Coresidence variables } \\
\hline Coresides with child 0 to 5 & -0.0443 & $* * *$ & 0.203 & -0.0369 & $* * *$ & 0.171 \\
\hline Coresides with child 6 to 12 & -0.0345 & $\star * \star$ & 0.201 & -0.0344 & $* * *$ & 0.174 \\
\hline Coresides with child 13 to 17 & 0.0144 & ** & 0.253 & -0.0179 & ** & 0.083 \\
\hline Coresides with child 0 to 5 , no adult child at home & 0.0050 & & 0.017 & 0.0195 & & 0.018 \\
\hline Coresides with child 6 to 12 , no adult child at home & 0.0514 & $* * *$ & 0.042 & 0.0400 & $* *$ & 0.024 \\
\hline Coresides with teenager, no adult child at home & -0.0195 & ** & 0.097 & 0.0634 & $* \star *$ & 0.020 \\
\hline Coresides with parents or parents in law & 0.0774 & $\star * *$ & 0.033 & 0.0337 & $* * *$ & 0.036 \\
\hline \multicolumn{7}{|l|}{ Individual Demographics } \\
\hline \multicolumn{7}{|l|}{ Age (Base case: Age 50 to 54 ) } \\
\hline Age 55 to 59 & -0.0918 & $* * *$ & 0.241 & -0.1001 & $* * *$ & 0.219 \\
\hline Age 60 to 64 & -0.1527 & $* * *$ & 0.191 & -0.1344 & $* * *$ & 0.206 \\
\hline Age 65 to 69 & -0.1762 & $* * *$ & 0.147 & -0.1510 & $* * *$ & 0.165 \\
\hline Age 70 to 74 & -0.2029 & $* * *$ & 0.108 & -0.1624 & $\star * *$ & 0.118 \\
\hline \multicolumn{7}{|l|}{ Education (Base case: graduated middle school) } \\
\hline Did not graduate primary school & -0.1827 & $\star * \star$ & 0.724 & -0.0306 & $\star \star * \star$ & 0.299 \\
\hline Graduated primary school or attend middle school & -0.1051 & $* * *$ & 0.191 & -0.0121 & $* *$ & 0.359 \\
\hline Attended high school or higher & 0.2023 & $\star * \star$ & 0.038 & 0.1265 & $\star \star * \star$ & 0.144 \\
\hline \multicolumn{7}{|l|}{ Current Marital Status (Base case: currently married) } \\
\hline Never married & -0.0505 & & 0.003 & 0.0100 & & 0.002 \\
\hline Widowed & -0.0091 & * & 0.300 & -0.0226 & $\star \star * *$ & 0.186 \\
\hline Divorced & 0.0168 & & 0.007 & 0.0564 & $* *$ & 0.008 \\
\hline \multicolumn{7}{|l|}{ Other individual level demographics } \\
\hline Agricultural worker in household & 0.1178 & $* * *$ & 0.269 & 0.5523 & $* * *$ & 0.210 \\
\hline Muslim & -0.0171 & & 0.016 & -0.0012 & & 0.013 \\
\hline \multicolumn{7}{|l|}{ Contextual Variables } \\
\hline \multicolumn{7}{|l|}{ Prefecture level variables } \\
\hline Percent Muslim & 0.0010 & ** & 1.271 & -0.0008 & * & 1.198 \\
\hline Unemployment rate & -0.0005 & ** & 15.660 & -0.0066 & $* * *$ & 4.985 \\
\hline Sex ratio at birth & 0.0419 & * & 1.082 & 0.0027 & & 1.218 \\
\hline Differential in male and female illiteracy rate & 0.0015 & $* * *$ & 20.779 & 0.0029 & $* * *$ & 10.134 \\
\hline \multicolumn{7}{|l|}{ Provincial level variables } \\
\hline Urban income & -0.0464 & $* * *$ & 5.119 & 0.0003 & $* *$ & 66.021 \\
\hline GDP growth rate & 0.0169 & $* * *$ & 9.231 & -0.0032 & * & 9.108 \\
\hline
\end{tabular}


Table 3b: Comparison of the Determinants of Labor Force Participation for Urban Non-Migrant Men, Aged 50 to 74

\begin{tabular}{|c|c|c|c|c|c|c|}
\hline \multirow{2}{*}{ Coresidence with adult children variables } & \multicolumn{3}{|c|}{1982} & \multicolumn{3}{|c|}{2000} \\
\hline & \multicolumn{2}{|c|}{ Marginal Effect } & \multirow{2}{*}{$\begin{array}{r}\text { Means } \\
0.749\end{array}$} & \multicolumn{2}{|c|}{ Marginal Effect } & Means \\
\hline Coresides with adult children & 0.2147 & $* * *$ & & -0.0384 & & 0.566 \\
\hline Residual of coresidence with adult child & -0.2795 & $* * *$ & 0.000 & -0.0084 & & 0.000 \\
\hline \multicolumn{7}{|l|}{ Other Coresidence variables } \\
\hline Coresides with child 0 to 5 & -0.0288 & $* * *$ & 0.159 & -0.0453 & $* \star *$ & 0.159 \\
\hline Coresides with child 6 to 12 & -0.0263 & $* * *$ & 0.205 & -0.0372 & $* \star *$ & 0.142 \\
\hline Coresides with child 13 to 17 & -0.0002 & & 0.322 & -0.0062 & & 0.086 \\
\hline Coresides with child 0 to 5 , no adult child at home & 0.0078 & & 0.013 & 0.0013 & & 0.016 \\
\hline Coresides with child 6 to 12 , no adult child at home & 0.0513 & $* \star \star$ & 0.036 & 0.0005 & & 0.021 \\
\hline Coresides with teenager, no adult child at home & -0.0070 & & 0.085 & 0.0243 & & 0.018 \\
\hline Coresides with parents or parents in law & 0.0719 & $* * *$ & 0.054 & 0.0478 & $* \star *$ & 0.049 \\
\hline \multicolumn{7}{|l|}{ Individual Demographics } \\
\hline \multicolumn{7}{|l|}{ Age (Base case: Age 50 to 54 ) } \\
\hline Age 55 to 59 & -0.2079 & $* \star \star$ & 0.244 & -0.2430 & $* * *$ & 0.215 \\
\hline Age 60 to 64 & -0.4475 & $* * *$ & 0.193 & -0.5020 & $* * *$ & 0.201 \\
\hline Age 65 to 69 & -0.5656 & $* * *$ & 0.140 & -0.5427 & $* * *$ & 0.169 \\
\hline Age 70 to 74 & -0.6504 & $* \star *$ & 0.086 & -0.5521 & $* * *$ & 0.116 \\
\hline \multicolumn{7}{|l|}{ Education (Base case: graduated middle school) } \\
\hline Did not graduate primary school & -0.1147 & $* * *$ & 0.275 & 0.0651 & $* * *$ & 0.081 \\
\hline Graduated primary school or attend middle school & -0.1071 & $* * *$ & 0.433 & 0.0125 & & 0.347 \\
\hline Attended high school or higher & 0.1419 & $* * *$ & 0.110 & 0.1061 & $* * *$ & 0.280 \\
\hline \multicolumn{7}{|l|}{ Current Marital Status (Base case: currently married) } \\
\hline Never married & -0.0484 & ** & 0.015 & -0.0536 & * & 0.016 \\
\hline Widowed & -0.0223 & ** & 0.100 & -0.0598 & $* * *$ & 0.058 \\
\hline Divorced & 0.0205 & & 0.014 & -0.0331 & & 0.011 \\
\hline \multicolumn{7}{|l|}{ Other individual level demographics } \\
\hline Agricultural worker in household & 0.2333 & $* * *$ & 0.274 & 0.5609 & $* * *$ & 0.222 \\
\hline Muslim & 0.0260 & & 0.016 & -0.0028 & & 0.013 \\
\hline \multicolumn{7}{|l|}{ Contextual Variables } \\
\hline \multicolumn{7}{|l|}{ Prefecture level variables } \\
\hline Percent Muslim & 0.0008 & & 1.431 & -0.0014 & ** & 1.180 \\
\hline Unemployment rate & -0.0015 & $* \star *$ & 15.814 & -0.0087 & $* \star *$ & 4.909 \\
\hline Sex ratio at birth & 0.1790 & $* \star \star$ & 1.080 & 0.0095 & & 1.222 \\
\hline Differential in male and female illiteracy rate & -0.0020 & $* \star \star$ & 20.435 & 0.0011 & & 10.178 \\
\hline \multicolumn{7}{|l|}{ Provincial level variables } \\
\hline Urban income & -0.0166 & $* * *$ & 5.097 & 0.0022 & $* * *$ & 66.235 \\
\hline GDP growth rate & 0.0101 & $* \star *$ & 9.189 & 0.0066 & $* *$ & 9.118 \\
\hline
\end{tabular}


Table 3c: Comparison of the Determinants of Labor Force Participation for Rural Women Aged 50 to 74

\begin{tabular}{|c|c|c|c|c|c|c|}
\hline \multirow{2}{*}{ Coresidence with adult children variables } & \multicolumn{3}{|c|}{1982} & \multicolumn{3}{|c|}{2000} \\
\hline & \multicolumn{2}{|c|}{ Marginal Effect } & \multirow{2}{*}{$\begin{array}{l}\text { Means } \\
0.770\end{array}$} & \multicolumn{2}{|c|}{ Marginal Effect } & Means \\
\hline Coresides with adult children & -0.3052 & $* * *$ & & -0.2849 & $* \star \star$ & 0.614 \\
\hline Residual of coresidence with adult child & 0.1625 & $* * *$ & 0.000 & 0.1366 & $* * *$ & -0.001 \\
\hline \multicolumn{7}{|l|}{ Other Coresidence variables } \\
\hline Coresides with child 0 to 5 & -0.0737 & $* \star *$ & 0.262 & -0.0685 & $* \star *$ & 0.235 \\
\hline Coresides with child 6 to 12 & -0.0310 & $* * *$ & 0.326 & -0.1049 & $* * *$ & 0.239 \\
\hline Coresides with child 13 to 17 & 0.0121 & ** & 0.411 & -0.0895 & $* \star *$ & 0.126 \\
\hline Coresides with child 0 to 5 , no adult child at home & 0.0440 & $* \star *$ & 0.018 & 0.0551 & $* * *$ & 0.038 \\
\hline Coresides with child 6 to 12 , no adult child at home & 0.0599 & $* \star \star$ & 0.064 & 0.1102 & $* \star \star$ & 0.039 \\
\hline Coresides with teenager, no adult child at home & -0.0051 & & 0.161 & 0.1303 & $* * *$ & 0.032 \\
\hline Coresides with parents or parents in law & 0.0578 & $* \star *$ & 0.031 & 0.0733 & $* * *$ & 0.048 \\
\hline \multicolumn{7}{|l|}{ Individual Demographics } \\
\hline \multicolumn{7}{|l|}{ Age (Base case: Age 50 to 54 ) } \\
\hline Age 55 to 59 & -0.1145 & $* * *$ & 0.237 & -0.1289 & $* * *$ & 0.218 \\
\hline Age 60 to 64 & -0.2124 & $* * *$ & 0.204 & -0.2749 & $* * *$ & 0.187 \\
\hline Age 65 to 69 & -0.2583 & $* * *$ & 0.165 & -0.3946 & $* * *$ & 0.168 \\
\hline Age 70 to 74 & -0.2724 & $* * *$ & 0.121 & -0.5038 & $* * *$ & 0.131 \\
\hline \multicolumn{7}{|l|}{ Education (Base case: graduated middle school) } \\
\hline Did not graduate primary school & -0.2202 & $* * *$ & 0.943 & -0.1211 & $* \star *$ & 0.516 \\
\hline Graduated primary school or attend middle school & -0.1009 & $* * *$ & 0.049 & -0.0164 & & 0.419 \\
\hline Attended high school or higher & 0.1869 & $* * *$ & 0.002 & 0.0852 & $* * *$ & 0.007 \\
\hline \multicolumn{7}{|l|}{ Current Marital Status (Base case: currently married) } \\
\hline Never married & 0.0808 & ** & 0.003 & -0.1485 & ** & 0.002 \\
\hline Widowed & -0.0254 & $* * *$ & 0.343 & -0.0654 & $* * *$ & 0.215 \\
\hline Divorced & 0.0668 & ** & 0.004 & -0.0076 & & 0.003 \\
\hline \multicolumn{7}{|l|}{ Other individual level demographics } \\
\hline Agricultural worker in household & 0.2521 & $* \star \star$ & 0.834 & 0.6850 & 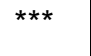 & 0.843 \\
\hline Muslim & 0.0865 & $* * *$ & 0.011 & 0.0668 & ** & 0.014 \\
\hline \multicolumn{7}{|l|}{ Contextual Variables } \\
\hline \multicolumn{7}{|l|}{ Prefecture level variables } \\
\hline Percent Muslim & 0.0026 & $* \star *$ & 1.127 & -0.0002 & & 1.513 \\
\hline Unemployment rate & -0.0043 & $* \star *$ & 5.090 & -0.0340 & $* * *$ & 2.977 \\
\hline Sex ratio at birth & 0.0071 & & 1.081 & 0.0247 & $* * *$ & 1.256 \\
\hline Differential in male and female illiteracy rate & 0.0047 & $* * *$ & 29.778 & 0.0033 & $* * *$ & 12.161 \\
\hline \multicolumn{7}{|l|}{ Provincial level variables } \\
\hline Urban income & 0.0000 & & 277.298 & 0.0000 & & 2347.630 \\
\hline GDP growth rate & 0.0035 & $* * *$ & 9.547 & -0.0192 & $* * *$ & 8.974 \\
\hline
\end{tabular}


Table 3d: Comparison of the Determinants of Labor Force Participation for Rural Men Aged 50 to 74

\begin{tabular}{|c|c|c|c|c|c|c|}
\hline \multirow{3}{*}{ Coresidence with adult children variables } & \multicolumn{3}{|c|}{1982} & \multicolumn{3}{|c|}{2000} \\
\hline & \multicolumn{2}{|c|}{ Marginal Effect } & \multirow[t]{2}{*}{ Means } & \multicolumn{2}{|c|}{ Marginal Effect } & \multirow[t]{2}{*}{ Means } \\
\hline & & & & & & \\
\hline Coresides with adult children & -0.3549 & $\star * *$ & 0.719 & -0.2207 & $\star \star \star *$ & 0.563 \\
\hline Residual of coresidence with adult child & 0.3812 & $\star * *$ & 0.000 & 0.1534 & $* * *$ & -0.001 \\
\hline \multicolumn{7}{|l|}{ Other Coresidence variables } \\
\hline Coresides with child 0 to 5 & -0.0779 & $\star * *$ & 0.222 & -0.0314 & $\star \star \star *$ & 0.219 \\
\hline Coresides with child 6 to 12 & -0.0564 & $* * *$ & 0.360 & -0.0595 & $* * *$ & 0.206 \\
\hline Coresides with child 13 to 17 & -0.0018 & & 0.480 & -0.0441 & $* \star *$ & 0.136 \\
\hline Coresides with child 0 to 5 , no adult child at home & 0.0029 & & 0.017 & -0.0032 & & 0.033 \\
\hline Coresides with child 6 to 12 , no adult child at home & 0.0642 & $* * *$ & 0.062 & 0.0570 & $\star \star \star *$ & 0.034 \\
\hline Coresides with teenager, no adult child at home & -0.0019 & & 0.153 & 0.0398 & $* * *$ & 0.030 \\
\hline Coresides with parents or parents in law & 0.0156 & & 0.053 & 0.0103 & & 0.068 \\
\hline \multicolumn{7}{|l|}{ Individual Demographics } \\
\hline \multicolumn{7}{|l|}{ Age (Base case: Age 50 to 54 ) } \\
\hline Age 55 to 59 & -0.1517 & $* * *$ & 0.253 & -0.1244 & $* * *$ & 0.227 \\
\hline Age 60 to 64 & -0.3699 & $* * *$ & 0.201 & -0.3040 & $* * *$ & 0.199 \\
\hline Age 65 to 69 & -0.5431 & $* * *$ & 0.153 & -0.4555 & $* * *$ & 0.161 \\
\hline Age 70 to 74 & -0.6972 & $* * *$ & 0.098 & -0.6356 & $* * *$ & 0.114 \\
\hline \multicolumn{7}{|l|}{ Education (Base case: graduated middle school) } \\
\hline Did not graduate primary school & -0.0101 & & 0.562 & 0.0217 & *** & 0.204 \\
\hline Graduated primary school or attend middle school & 0.0055 & & 0.352 & 0.0343 & $* * *$ & 0.562 \\
\hline Attended high school or higher & -0.0108 & & 0.018 & -0.0490 & $* * *$ & 0.042 \\
\hline \multicolumn{7}{|l|}{ Current Marital Status (Base case: currently married) } \\
\hline Never married & -0.2109 & $\star \star * *$ & 0.030 & -0.0957 & *** & 0.047 \\
\hline Widowed & -0.1594 & $* * *$ & 0.162 & -0.0543 & $* * *$ & 0.106 \\
\hline Divorced & -0.1098 & $\star * *$ & 0.020 & -0.0072 & & 0.012 \\
\hline \multicolumn{7}{|l|}{ Other individual level demographics } \\
\hline Agricultural worker in household & 0.6221 & *** & 0.851 & 0.6743 & $* * *$ & 0.868 \\
\hline Muslim & 0.0537 & ** & 0.013 & 0.0431 & *** & 0.013 \\
\hline \multicolumn{7}{|l|}{ Contextual Variables } \\
\hline \multicolumn{7}{|l|}{ Prefecture level variables } \\
\hline Percent Muslim & -0.0003 & & 1.304 & 0.0001 & & 1.508 \\
\hline Unemployment rate & -0.0014 & $* * *$ & 5.216 & -0.0020 & *** & 2.998 \\
\hline Sex ratio at birth & 0.1001 & $* * *$ & 1.081 & 0.0070 & & 1.256 \\
\hline Differential in male and female illiteracy rate & -0.0017 & $* * *$ & 29.372 & -0.0010 & $* * *$ & 12.137 \\
\hline \multicolumn{7}{|l|}{ Provincial level variables } \\
\hline Urban income & -0.0003 & $* * *$ & 276.014 & 0.0000 & $* * *$ & 2338.830 \\
\hline GDP growth rate & 0.0150 & $* * *$ & 9.491 & 0.0021 & & 8.967 \\
\hline
\end{tabular}


Table 4: Decomposition of LFP Rate Changes

\begin{tabular}{|c|c|c|c|c|}
\hline & & $\begin{array}{l}\text { Actual difference } \\
\text { in LFP rate }\end{array}$ & Response effect & Attribute effect \\
\hline & & $\begin{array}{l}\text { (percentage point } \\
\text { differences in rates } \\
\text { between census } \\
\text { years) }\end{array}$ & $\begin{array}{l}\text { (differences } \\
\text { resulting from } \\
\text { changes in } \\
\text { coefficients) }\end{array}$ & $\begin{array}{l}\text { (differences resulting from } \\
\text { changes in mean } \\
\text { characteristics) }\end{array}$ \\
\hline Urban women & 2000 vs 1982 & -0.0200 & 0.0973 & -0.1173 \\
\hline Urban men & 2000 vs 1982 & -0.1875 & 0.1501 & -0.3375 \\
\hline Rural women & 2000 vs 1982 & 0.3107 & 0.2779 & 0.0328 \\
\hline Rural men & 2000 vs 1982 & 0.0735 & 0.3567 & -0.2832 \\
\hline
\end{tabular}

Note: This decomposition uses Borooah and Iyers (2005) methodology, which allows for pairwise comparisons based on the full sample's (in this case, including data from both census years) mean values of the X's 


\section{Bibliography}

Borooah, V.K. and S. Iyer. 2005. "The Decomposition of Inter-group differences in a Logit Model: Extending the Oaxaca-Blinder Approach with an Application to School Enrollment in India," Journal of Economic and Social Measurement 30(4), 279-293.

Cai, Fang, John Giles, Philip O'Keefe, and Dewen Wang. 2012. The Elderly and Old Age Support in Rural China: Challenges and Prospects. The World Bank: Washington, D.C.

Carmichael, F. and S. Charles. 2003. "The Labour Market Costs of Community Care," Journal of Health Economics 22(5), 781-803.

Chang, Hongqin, Xiao-yuan Dong, and Fiona MacPhail. 2011. "Labor Migration and Time Use Patterns of the Left-behind Children and Elderly in Rural China," World Development 39(12): 2199-2210.

Chen, Feinian. 2005. "Residential Patterns of Parents and Their Married Children in Contemporary China: A Life Course Approach," Population Research and Policy Review, 24: 125-148.

Connelly, Rachel, Ken Roberts and Zhenzhen Zheng. 2012. “The Role that Children's Education Plays in the Migration Decisions of Chinese Rural Women," Journal of Contemporary China 21(73), January, 93-111.

Ettner, Susan L. 1995. "The Impact of 'Parent Care' on Female Labor Supply Decisions." Demography 32, no. 1: 63-80.

Gendell, Murray. 2008. "Older workers: increasing their labor force participation and hours of work," Monthly Labor Review. January : 41-54.

Giles, John, Dewen Wang, and Wei Cai. 2011. "The Labor Supply and Retirement Behavior of China's Older Workers and Elderly in Comparative Perspective," Policy Research Working Paper 5853, World Bank, Development Research Group.

Heitmueller, Axel and Kirsty Inglis. 2007. "The Earnings of Informal Carers: Wage Differentials and Opportunity Costs," Journal of Health Economics 26, 821-841.

Johnson, R. and LoSasso, A. 2006. “The Impact of Elder Care of Women's Labor Supply," Economic Inquiry 43(3), 195-210.

Liu, Lan, Xiaoyuan Dong, Xiaoying Zheng. 2010. "Parental Care and Married Women's Labor Supply in Urban China," Feminist Economics 16(3), July, 169-92. 
Maurer-Fazio, Margaret, Rachel Connelly, Chen Lan, and Lixin Tang. 2011.

"Childcare, Eldercare, and Labor Force Participation of Urban Women in China: 1982-2000," Journal of Human Resources 46(2), Spring, 261-294.

Maurer-Fazio, Margaret, James Hughes, and Dandan Zhang. 2005. "Economic Reform and Changing Patterns of Labor Force Participation in Urban and Rural China," University of Michigan, William Davidson Institute Working Paper Series, August, Working Paper Number 787, 1-39.

Maurer-Fazio, Margaret, James Hughes, and Dandan Zhang. 2007. “An Ocean Formed from One Hundred Rivers: The Effects of Ethnicity, Gender, Marriage, and Location on Labor Force Participation in Urban China, Feminist Economics 13(34), 159-187.

Maurer-Fazio, Margaret, James Hughes, and Dandan Zhang. 2010. "A Comparison and Decomposition of Reform-Era Labor Force Participation Rates of China's Ethnic Minorities and Han Majority," International Journal of Manpower 31(2), 138162.

Meng, Xin and Chuliang Luo. 2008."What Determines Living Arrangements of the Elderly in Urban China," in Inequality and Public Policy Bjorn Gustafsson, Shi Li, and Terry Sicular, editors, Cambridge: Cambridge University Press.

Ren Mu and Dominique van de Walle. 2011. "Left Behind to Farm? Women's Labor Reallocation in Rural China," Labour Economics 18:S83-S97

Roberts, Kenneth, Rachel Connelly, Zhenming Xie and Zhenzhen Zheng. 2004. "Patterns of Temporary Migration of Rural Women from Anhui and Sichuan Provinces of China," The China Journal 52, 49-70.

Stern, Steven. 1996. "Measuring Child Work and Residence Adjustments to Parents' Long-Term Care Needs," The Gerontologist 36(1), 76-87.

Terza, Joseph V., Anirban Basu, and Paul J. Rathouz. 2008. “Two-stage Residual Inclusion Estimation: Addressing Endogeneity in Health Econometric Modeling," Journal of Health Economics 27, 531-543.

U.S. Department of Labor, "Quick Facts on Older Workers," The U.S. Department of Labor Home Page. Jan. 2005. Web, accessed 29 Jan. 2014.

<http://www.dol.gov/wb/factsheets/Qf-olderworkers55.htm>.

Wang, Feng. 2012. "Racing toward the Precipice," in China Economic Quarterly, June, pp. 17-21. 
Wolf, Douglas A., and Beth J. Soldo. 1994. "Married Women's Allocation of Time to Employment and Care of Elderly Parents." Journal of Human Resources 29(4), 1259-1276.

Zeng, Zhen and Yu Xie, 2011. "The Effects of Grandparents on Children's Schooling:Evidence from Rural China" Center for Demography and Ecology, University of Wisconsin-Madison, CDE Working Paper No. 2011-11.

Zeng, Yi and Zhengdian Wang. 2004. "Family and Changes of Living Arrangements of the Elderly in China," Chinese Journal of Population Science. No. 5, October 1, pp.2-8.(in Chinese)

Zhang, Qian Forrest, 2004. "Economic Transition and New Patterns of Parent-Adult Child Coresidence in Urban China," Journal of Marriage and the Family 66, 1231-1245. 